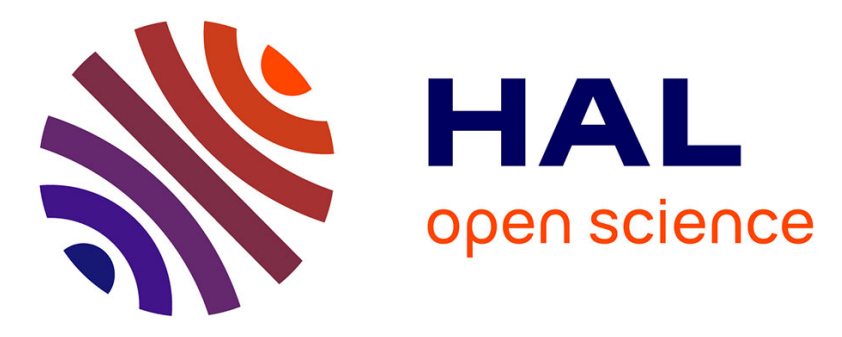

\title{
Novel class of nanostructured metallic glass films with superior and tunable mechanical properties
}

\author{
Matteo Ghidelli, Andrey Orekhov, Andrea Li Bassi, Giancarlo Terraneo, \\ Philippe Djemia, Gregory Abadias, Magnus Nord, Armand Béché, Nicolas
}

Gauquelin, Johan Verbeeck, et al.

\section{To cite this version:}

Matteo Ghidelli, Andrey Orekhov, Andrea Li Bassi, Giancarlo Terraneo, Philippe Djemia, et al.. Novel class of nanostructured metallic glass films with superior and tunable mechanical properties. Acta Materialia, 2021, 213, pp.116955. 10.1016/j.actamat.2021.116955 . hal-03241496

\section{HAL Id: hal-03241496 \\ https://hal.science/hal-03241496}

Submitted on 2 Jun 2021

HAL is a multi-disciplinary open access archive for the deposit and dissemination of scientific research documents, whether they are published or not. The documents may come from teaching and research institutions in France or abroad, or from public or private research centers.
L'archive ouverte pluridisciplinaire HAL, est destinée au dépôt et à la diffusion de documents scientifiques de niveau recherche, publiés ou non, émanant des établissements d'enseignement et de recherche français ou étrangers, des laboratoires publics ou privés. 


\section{Novel class of nanostructured metallic glass films with superior and tunable mechanical properties}

M. Ghidelli, ${ }^{1,2,+,}{ }^{,}$, A. Orekhov ${ }^{3,4,5,+}$, A. Li Bassi ${ }^{1}$, G. Terraneo ${ }^{6}$, P. Djemia², G. Abadias ${ }^{7}$, M . Nord ${ }^{4,5,8}$, A. Béché $^{4,5}$, N. Gauquelin ${ }^{4,5}$, J. Verbeeck ${ }^{4,5}$, J.-P. Raskin ${ }^{9}$, D. Schryvers ${ }^{4,5}$, T. Pardoen ${ }^{3}$, H. Idrissi ${ }^{3,4 *}$

${ }^{1}$ Dipartimento di Energia, Laboratorio Materiali Micro e Nanostrutturati, Politecnico di M ilano, via Ponzio 34/3, I-20133 Milano, Italy

'Laboratoire des Sciences des Procédés et des M atériaux (LSPM), CNRS, Université Sorbonne Paris Nord, 93430, Villetaneuse, France

${ }^{3}$ Institute of M echanics, M aterials and Civil Engineering, UCLouvain, B-1348, Louvain-la-Neuve, Belgium.

${ }^{4}$ Electron M icroscopy for M aterials Science (EM AT), University of Antwerp, Groenenborgerlaan 171, B2020 Antwerp, Belgium.

${ }^{5}$ NANOlab Center of Excellence, University of Antwerp, Groenenborgerlaan 171, B-2020 Antwerp, Belgium.

${ }^{6}$ Laboratory of Supramolecular and Bio-Nanomaterials (SupraBioNanoLab), Department of Chemistry, Materials, and Chemical Engineering "Giulio Natta", Politecnico di Milano, Milano, 20131, Italy.

'Institut Pprime, UPR 3346, CNRS-Université de Poitiers-ENSM A, 11 Boulevard Marie et Pierre Curie, TSA 41123, 86073 Poitiers Cedex 9, France.

${ }^{8}$ Department of Physics, Norwegian University of Science and Technology (NTNU), NO-7491 Trondheim, Norway.

9 Institute of information and communication technologies, electronics and applied mathematics, ICTEAM, UCLouvain, B-1348, Louvain-la-Neuve, Belgium.

*Corresponding authors: matteo.ghidelli@Ispm.cnrs.fr and hosni.idrissi@uclouvain.be these authors equally contributed: Matteo Ghidelli, Andrey Orekhov 


\begin{abstract}
A novel class of nanostructured $\mathrm{Zr}_{50} \mathrm{Cu}_{50}$ (\%at.) metallic glass films with superior and tunable mechanical properties is produced by pulsed laser deposition. The process can be controlled to synthetize a wide range of film microstructures including dense fully amorphous, amorphous embedded with nanocrystals and amorphous nano-granular. A unique dense self-assembled nano-laminated atomic arrangement characterized by alternating Cu-rich and Zr/O-rich nanolayers with different local chemical enrichment and amorphous or amorphous-crystalline composite nanostructure has been discovered, while significant in-plane clustering is reported for films synthetized at high deposition pressures. This unique nanoarchitecture is at the basis of superior mechanical properties including large hardness and elastic modulus up to 10 and $140 \mathrm{GPa}$, respectively and outstanding total elongation to failure ( $>9 \%)$, leading to excellent strength/ductility balance, which can be tuned by playing with the film architecture. These results pave the way to the synthesis of novel class of engineered nanostructured metallic glass films with high structural performances attractive for a number of applications in microelectronics and coating industry.
\end{abstract}

\title{
Keywords
}

Nanostructured thin films; metallic glasses; pulsed laser deposition; high resolution TEM ; in-situ TEM mechanical testing.

\section{Introduction}

Bulk metallic glasses (BM Gs) are characterized by unique mechanical properties including high yield strength ( $\geq 2 \mathrm{GPa}$ ) and elastic deformation $(\sim 2 \%)[1,2]$. However, their Achilles heel is the premature catastrophic failure mechanism occurring at room temperature with the deformation localized in narrow ( $10 \mathrm{~nm}$-thick) shear bands (SBs) [3]. However, this brittle-like behavior can be mitigated by reducing the 
size of the sample down to the sub-micrometer scale $[4,5]$. This finding promoted the exploration of thin films metallic glasses (TFM Gs) reporting homogeneous deformation with the delaying or even suppression of SB formation, while further enhancing the mechanical performances towards outstanding yield strength/ ductility balance up to $\sim 3.5 \mathrm{GPa}$ and $\sim 15 \%$ and large hardness, respectively [6-8].

These superior mechanical properties pushed further the research towards the development of nanostructured TFMGs, exploiting also strengthening strategies so far adapted to crystalline materials including e.g. multilayer configurations [9-11] and grain refinement [12-14]. In the first case, Kim et al. [10] show that alternating $120 \mathrm{~nm}$-thick layers of $\mathrm{Cu}_{50} \mathrm{Zr}_{50}$ (\% at.) with $16 \mathrm{~nm}$-thick nanocrystalline $\mathrm{Cu}$ results in a tensile strength and fracture strain up to $\sim 2.5 \mathrm{GPa}$ and $\sim 4 \%$, respectively. Along the second path analogous to the efforts for "grain refinement", nanoglasses (NGs) have been synthetized showing a structure similar to nanocrystalline materials exhibiting interfacial regions between amorphous nanoparticles with a high free volume content [12-14]. This enables the activation of shear transformation zones (STZs) at the glass-glass interfaces, favoring distributed plastic deformation without the percolation in a single catastrophic SB [12]. A similar mechanism has been found for amorphous materials embedded with nanocrystals as demonstrated by Hajlaoui et al. [15] for several Zr-based BM Gs. Pre-annealing can induce dispersions of extremely fine crystallites ( $2 \mathrm{~nm}$ diameter) which lead to significant improvement in homogenous plastic flow ability up to $10 \%$ in compression due to constraint put on SB propagation.

Despite all these findings, the synthesis of nanostructured TFM Gs with tuned microstructure as well as the understanding of the fundamental deformation and fracture behavior is still a quite open field. For instance, the synthesis of NGs is usually carried out in two-steps, involving the deposition of NGs powders, followed by a compaction phase at large ( $>1 \mathrm{GPa}$ ) pressure [12]. This process results in a powderassembled film with a lower yield strength compared to compact TFMG counterparts and limits the possibility to tune the microstructure [16]. Also, the synthesis of nanocomposite films relies on a sequence of different deposition steps with potential issues due to the development of weak interfaces $[9,10]$. 
In this context, we discovered that pulsed laser deposition (PLD) allows the synthesis of TFM Gs with unique nanolayered structure, resulting in outstanding and tunable mechanical behavior. Among physical vapor deposition techniques, PLD is known for its potential to accurately tune the film morphology by simply changing the background gas pressure allowing the synthesis of compact [17] or nanostructured films [18]. To the best of our knowledge, PLD has never been employed for the synthesis of nanostructured TFM Gs before.

The objectives of this work are to deposit TFM Gs by PLD, to characterize the nanostructure, reveal the mechanical properties and propose a rationale to understand the link between microstructure and performances. For this purpose, dense fully amorphous, amorphous-crystalline composite and amorphous nano-granular nanostructured glassy films with $\mathrm{Zr}_{50} \mathrm{Cu}_{50}(\%$ at.) composition are processed depending on the background gas pressure during deposition. High resolution scanning transmission electron microscopy (HR-STEM) imaging and spectroscopy in combination with 4D-STEM reveal a unique self-assembled amorphous and amorphous-crystalline nano-laminated structure with different local chemical enrichment (Cu-rich and Zr/O-rich nanolayers). We also report attractive mechanical properties with Young's modulus and hardness up to 140 and $10 \mathrm{GPa}$, respectively, while quantitative in-situ TEM tensile tests show outstanding yield strength $(\sim 2.6 \mathrm{GPa})$ and total elongation to failure $(>9 \%)$, which can be tuned by controlling the nanoclustering.

\section{Experimental}

\subsection{Thin film deposition and structural characterization}

$\mathrm{Zr}_{50} \mathrm{Cu}_{50}$ (\% at.) thin films have been deposited by ablating a $\mathrm{Zr}_{50} \mathrm{Cu}_{50}(99.99 \%$ pure, provided by 'M aTecK') target with a ns-pulsed laser ( $\mathrm{Nd}: Y A G, 1^{\text {st }}$ harmonic, $\lambda=1064 \mathrm{~nm}$, repetition rate $10 \mathrm{~Hz}$, pulse duration 5-7 ns). The laser fluence on the target was set at about $\sim 20.0 \mathrm{~J} / \mathrm{cm}^{2}$ and the laser pulse energy was 1850 mJ. Si (100) and soda-lime glass were used as substrates after delicate cleaning in ultrasonic bath with isopropanol. The substrates have been mounted on a rotating sample holder at a fixed target-to- 
substrate distance $\left(d_{t-s}\right)$ of $70 \mathrm{~mm}$. All the depositions have been carried out at room temperature in vacuum $\left(2 \cdot 10^{-3} \mathrm{~Pa}\right)$ or within a pure He background gas varying the pressure from 5 up to $200 \mathrm{~Pa}$ in order to induce cluster-assembled growth. The films thickness was equal to $500 \mathrm{~nm}$. The deposition rate for the film deposited in low vacuum $\left(2.1 \times 10^{-3} \mathrm{~Pa}\right)$ was $\sim 1.20 \mathrm{~nm} / \mathrm{s}$, while for films deposited at large background gas pressures (10 and $100 \mathrm{~Pa}$ ) the deposition rate was higher due to the cluster-assembled growth, equal to $1.39 \mathrm{~nm} / \mathrm{s}$. A field emission scanning electron microscope (FE-SEM) Zeiss Supra 40 equipped with energy dispersive X-ray spectroscopy (EDX) was used to perform morphological/compositional characterization analyzing films deposited on Si (100) substrate. X-ray diffraction (XRD) patterns were collected using a Bruker D8 Advance X-ray diffractometer at $293 \mathrm{~K}$ (Cu Kal radiation - 1.5406 A). The measurements were carried out under grazing incidence geometry with an incidence angle of $0.95^{\circ}$ to avoid substrate signal and step-scan in the range of $20-90^{\circ}$. Data were acquired overnight by Lynx Eye detector in continuous scanning mode with a step size of $0.14^{\circ}$.

\subsection{Ex-situ and in-situ Transmission Electron M icroscopy}

Sample preparation: For ex-situ high-resolution STEM, STEM-EDX and NBED 4D-STEM analysis, crosssectional foils were prepared using a dual-beam focused ion beam (FIB) instrument (FEI Helios Nanolab 650). A Pt protection layer was deposited in two steps - by electron beam, then by ion beam- in order to avoid FIB damage at the sample surface. The FIB foils were thinned to a thickness $<50 \mathrm{~nm}$. An ion beam of $2 \mathrm{kV} / 0.2 \mathrm{nA}$ was employed for final thinning of the specimen and to minimize irradiation damage generated during high-voltage FIB thinning. For in-situ push-to-pull (PTP) experiments in the TEM , a crosssectional thick FIB specimen with dimensions of about $10 \times 2 \times 4 \mu \mathrm{m}^{3}$ was cut and mounted into the PTP device using an Omniprobe micromanipulator. The in-situ specimen was thus thinned directly on the PTP device. The central region of the specimen was thinned to a thickness of about $150 \mathrm{~nm}$, and at the final stage, the Pt protective layer and the substrate were cut off to obtain a free-standing ZrCu film with dimensions $2 \times 0.4 \times 0.15 \mu \mathrm{m}^{3}$ (Fig. 5b, c). 
High-resolution STEM and EDX mapping: A state-of-the-art spherical aberration-corrected FEI Titan X-AntEM transmission electron microscope equipped with a D-Corr probe aberration corrector and highly efficient SuperX system was used. The samples were plasma-cleaned prior to loading into the electron microscope in a Fischione Plasma Cleaner Model 1020 for up to $30 \mathrm{~s}$ with an $75 \% \mathrm{Ar} / 25 \% \mathrm{O}_{2}$ gas and a plasma power of about $30 \%$ to remove surface contaminations from the sample and the specimen holder. High-resolution HAADF-STEM images were acquired at $300 \mathrm{kV}$ using a convergence semi-angle $\alpha$ of 21 mrad, 50 pA probe current. STEM -EDX maps were acquired at $200 \mathrm{kV}$ using a convergence semi-angle $\alpha$ of $22 \mathrm{mrad}, 150 \mathrm{pA}$ probe current and exposure time of about 15-20 min.

4D STEM Nanobeam diffraction analysis: The term "4D-STEM" refers to recording 2D diffraction patterns in the reciprocal space, over a 2D grid of probe positions in the real space $[19,20]$. This technique allow detecting the medium range order (MRO) in amorphous materials [21-23] or specimens containing nanometer sized crystalline regions embedded in an amorphous matrix [24] (see Supplementary information for extended details about the 4D-STEM acquisition conditions and the post-treatment of the 4D-STEM data, S5-7). Large-scale 4D-STEM experiments have become possible thanks to two major technical developments: high speed and efficient direct electron detectors, and the widespread availability of computational power. FEI Titan X-Ant-EM transmission electron microscope operating at an accelerating voltage of $200 \mathrm{kV}$ was used. A convergence semi-angle $\alpha$ was adjusted to a value about 1.0 mrad in the $\mu$ Probe STEM mode with a $20 \mu \mathrm{m} \mathrm{C2}$ condenser aperture and large angle mode resulting in about $1.0 \mathrm{~nm}$ probe diameter measured in vacuum (see Supplementary information for more details, S57). The probe current was less than 30 pA. For 4D-STEM experiments, electron diffraction patterns were acquired at every probe position $[19,20,25]$ on a M edipix3 hybrid pixel direct electron detector (Quantum Detectors M erlin) [26] with a camera length of $185 \mathrm{~mm}$ and exposure time of $3 \mathrm{~ms}$. This detector offers a high frame rate and high efficiency enabling the detection of individual electrons without dark or read- 
out noise and a very high dynamic range. The 4D-STEM data was processed with custom-made scripts based on the open-source python libraries Hyperspy and pixStem [27, 28].

In-situ TEM Nanomechanical Testing: The in-situ uniaxial tensile experiments were conducted in a FEI Osiris microscope operating at $200 \mathrm{kV}$ in bright-field TEM mode with a beam current of about $2 \mathrm{nA}$. A 1 $\mu \mathrm{m}$ conductive diamond flat puncher indenter of the single-tilt PI 95 TEM Picolndenter (Bruker.Inc) was used. Tensile experiments were performed under load control mode with loading rate $0.1 \mu \mathrm{N} / \mathrm{sec}$. Applied force on the specimen was determined by removing the contribution of the spring stiffness from the raw force. The engineering stress was calculated by dividing the force in the specimen by the initial crosssectional area of the specimen. Sample thickness was measured in high-resolution mode of SEM with a resolution of $\sim 3 \mathrm{~nm}$ while the sample width and length were measured on the BF-TEM images. Videos with rate of 5 frames/sec were recorded and post-processed using home-made MATLAB scripts. The engineering strain was extracted by measuring the displacement directly on the specimen (i.e. the central small gauge length in Figures $5 b$ and $5 c$ ) using digital image correlation.

\subsection{Mechanical characterization with Brillouin light scattering (BLS) and Nanoindentation}

In a BLS experiment, a monochromatic incident light beam is inelastically scattered by the thermally excited acoustic waves with a frequency shifted by $\Psi$ that we can analyze thanks to a Sandercock tandem Fabry-Pérot interferometer. The BLS spectra were obtained at room temperature in air, varying the angle of incidence $\theta$ from $45^{\circ}$ to $65^{\circ}$, with typical acquisition times of $1 \mathrm{~h}$ and $200 \mathrm{~mW}$ of a p-polarized incident light with wavelength $\lambda=532 \mathrm{~nm}$. For these opaque films, the scattering mechanism is restricted to the scattering of light by the dynamical corrugation of the free surface by surface acoustic waves (SAWs) travelling parallel to the film plane. The sound velocity of SAWs is defined by $\mathrm{V}_{\text {SAW }}=\mathrm{F} \lambda /(2 \sin (\theta))$. For thick $(\sim \mu \mathrm{m})$ films, we can only observe the Rayleigh surface wave. The sound velocity $\left(V_{R} \sim 0.92 V_{S}\right)$ is closely related to the shear sound velocity $V_{S}=(G / \rho)^{1 / 2}$ where $G$ is the shear elastic modulus and $\rho$ the mass density measured by X-ray reflectivity (XRR, see Supplementary information, S2). The Poisson ratio ( $v$ ) 
was determined thanks to the relationship $v=1-2 \mathrm{G} / \mathrm{E}_{\mathrm{r}}$, using the shear modulus $\mathrm{G}=\mathrm{E} /(2(1+v))$ and the reduced elastic modulus $\mathrm{E}_{\mathrm{r}}=\mathrm{E} /\left(1-\nu^{2}\right)$ measured by nanoindentation.

Nanoindentation tests were performed with a diamond Berkovich tip mounted on an Agilent G200 Nanoindenter DCM II head. Prior to testing, the tip area function was calibrated using a fused silica reference. The nanoindentation measurements were performed under load-control mode at room temperature using the continuous stiffness measurements (CSM) method providing the current value of hardness with increasing indentation depth. The thermal drift rate has been limited to $0.05 \mathrm{~nm} \mathrm{~s}^{-1}$. Sixteen indents were performed in each sample. The maximum indentation depth was fixed at $500 \mathrm{~nm}$. The loading rate was imposed as equal to $0.05 \mathrm{~s}^{-1}$. The hardness was determined using the Oliver and Pharr method [29] at a reduced depth (depth/thickness, $\mathrm{h} / \mathrm{t}$ ) in between 0.1 and 0.15 which corresponds to a plateau values while avoiding substrate effects and surface artefacts (e.g. roughness effects). The reduced elastic moduli $\left(E_{r}\right)$ is calculated by using the Hay $\&$ Crawford [30] model to minimize the influence of the substrate. The extracted modulus shows a plateau for $h / t$ in between 0.05 and 0.1 . Finally, no pile-up has been observed similar to the nanoindentation results on ZrNi TFM Gs, Ref. [8].

\section{Results and Discussion}

\subsection{Synthesis and structural characterization}

Figs. 1a-d show SEM cross-sections of ZrCu films deposited at different background gas pressures from low vacuum $\left(2 \times 10^{-3} \mathrm{~Pa}\right)$ up to $100 \mathrm{~Pa}(\mathrm{He})$. Films deposited at low vacuum (a) are dense, resulting from the high energy of the ablated species several tens of eV/atom [31] with limited collisions rate and a large mean free path ("dense amorphous growth regime"). Upon landing on the substrate, the film growth mechanism is atom-by-atom with a high surface mobility, Refs. [32-34] (Fig. 1e). Cross-sectional SEM images reveal a smooth fracture surface with a regular corrugation pattern (width $\sim 5-10 \mathrm{~nm}$, Fig. 1a) constituting a typical fingerprint of TFM Gs cracking mechanism [35]. Nanostructuration phenomena occur upon increasing the background gas pressure. Films deposited at $8 \times 10^{-3}$ and 5 Pa (Fig. 1b) exhibit the 
nucleation of crystalline $\mathrm{ZrO}_{2}, \mathrm{Cu}$ and $\mathrm{ZrCu}$ phases as discussed below from XRD analysis ("transition growth regime") [36], while a nanogranular structure is observed when increasing the pressure up to 100 $\mathrm{Pa}$ (Figs. 1c-d, "amorphous nanogranular growth regime"). This nanogranular morphology arises from the confinement of atomic species within the ablation plume leading to formation of clusters that land on the substrate with a progressively lower energy when increasing the pressure, as found for PLD-deposited nanostructured oxides [17, 18] and metallic [32] films (Fig. 1f). These cluster-assembled films share features similar to NGs so far produced by a dual step process $[12,14]$. The mass density extracted by XRay Reflectivity (XRR) decreases from $7.4 \mathrm{gcm}^{-3}$ (as for sputter-deposited ZrCu TFM Gs [37]) down to 6.35 $\mathrm{gcm}^{-3}$ for films deposited at $2.1 \times 10^{-3}$ and $100 \mathrm{~Pa}$, respectively, as a result of the cluster-assembled growth.

The grazing incidence XRD (GIXRD) in Fig. $1 \mathrm{~g}$ of films deposited under low vacuum $\left(2 \times 10^{-3} \mathrm{~Pa}\right)$ reveals the presence of an amorphous first sharp diffraction peak (FSDP) located at $37.6^{\circ}$, as for $\mathrm{Zr}_{50} \mathrm{Cu}_{50}$ (\% at.) films produced by sputtering, reporting an average atomic distance of $0.235 \mathrm{~nm}[37,38]$. The full width at half maximum (FWHM) is $10.4^{\circ}$ indicating an amorphous structure as for binary Zr-based M Gs [37, 39]. Increasing the background gas pressure to $8.1 \times 10^{-3}$ and $5 \mathrm{~Pa}$, the films become more crystalline as shown by the presence of several peaks associated with the formation of nanocrystals. The unwanted presence of oxygen (0) during the deposition could be responsible for the undesired metal-oxide nanocrystals in Zr-Cu M G because of its high affinity with 0 even under extremely low concentration ( $0.14 \%$ at.), favoring nanocrystallization, see Refs. [36, 40, 41]. Specifically, in the $8.1 \times 10^{-3}$ and 5 Pa films, the observed peaks at $29,34,50,59,74$ and $82^{\circ}$ can be associated to the presence of the tetragonal $\mathrm{ZrO}_{2}$ phase (Figs. S1-S2 and [37]). At these specific depositions conditions, involving extremely high laser fluence, a small percentage of $\mathrm{O}$ can be incorporated/bonded with the $\mathrm{Zr}$-Cu atoms resulting in a transition regime with the formation of a dense film with some nanocrystallization. The formation of the $\mathrm{ZrO}_{2}$ nanocrystals unbalances the ratio between the two metals resulting in the development of Cu-rich clusters. In fact, the peaks around $42^{\circ}$ can be attributed to nanocrystalline $\mathrm{Zr}_{7} \mathrm{Cu}_{10}$ and $\mathrm{Zr}_{14} \mathrm{Cu}_{51}$ (Figs. S3-S6). These $\mathrm{Cu}$-enriched 
clusters have been already observed in Zr-Cu films in presence of Zr oxides [37]. Finally, we cannot exclude the presence of some fcc-Cu nanocrystals that could gradually decompose into $\mathrm{Cu}_{51} \mathrm{Zr}_{14}$ intermetallic (Figs. S7-S8).

As the pressure increases, films become again progressively amorphous with a shift of the FSDP at lower angles $\sim 32.5^{\circ}$ with larger atomic distances of $0.27 \mathrm{~nm}$. The FWHM is narrower than for films deposited at $2 \times 10^{-3} \mathrm{~Pa}$, decreasing to 5.9 and $7.2^{\circ}$ for films deposited at 10 and $100 \mathrm{~Pa}$, respectively. This indicates a marked local order, but with extended average bond lengths. This can be explained by the presence of $\mathrm{O}$ which can be incorporated in the film or which can induce some change in covalent bond behavior and local ordering but also a geometrical distortion (see discussion of Fig. 3) [42]. Nevertheless, the reduced kinetic energy of the ablated species and limited surface mobility prevents any crystallization, resulting in a cluster-assembled nanogranular amorphous film (Figs. 1c-d), as also reported for $\mathrm{WO}_{\mathrm{x}}$ films grown by PLD [42].
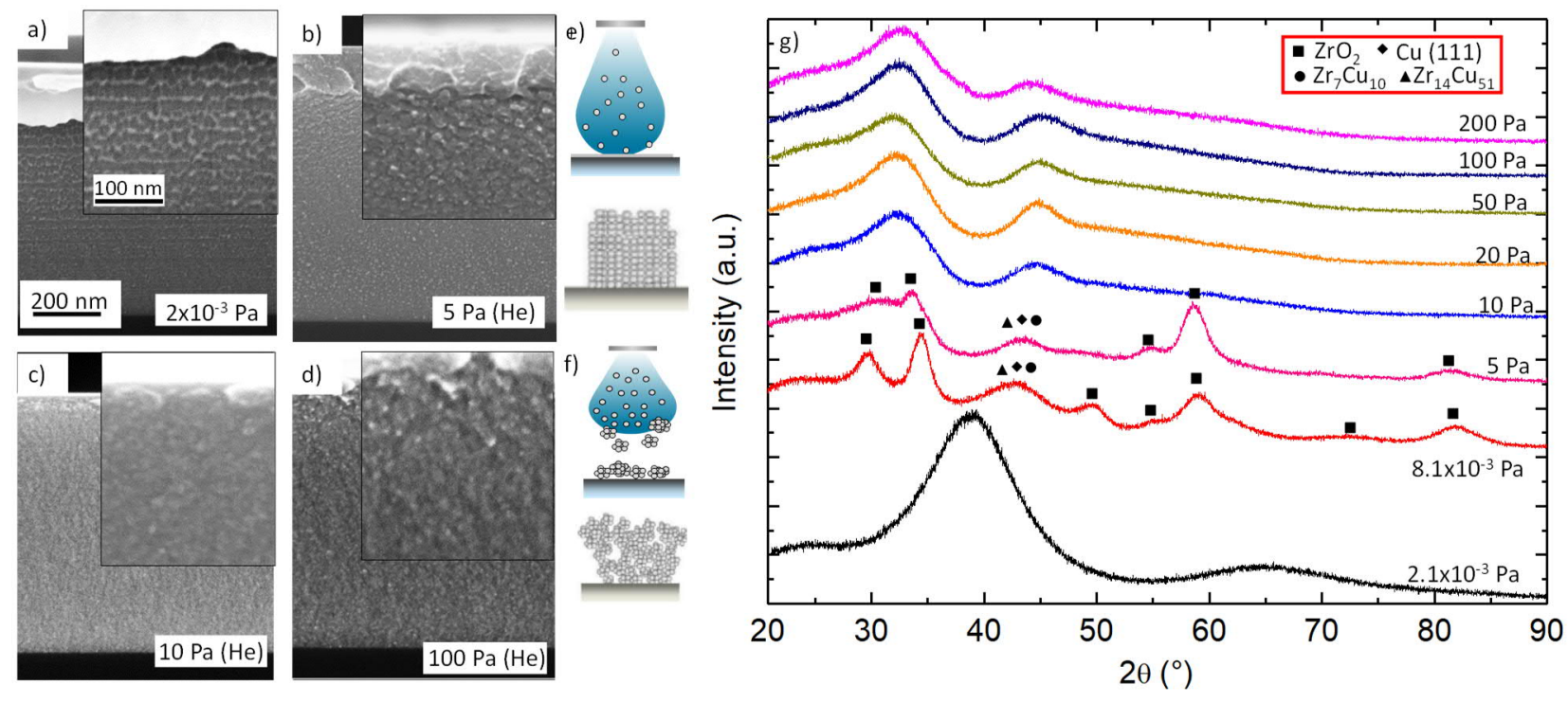

Fig. 1. (a-d) M orphological evolution of nanostructured $\mathrm{Zr}_{50} \mathrm{Cu}_{50}$ TFM Gs as a function of the background pressure during deposition. Deposition under low vacuum $\left(2 \times 10^{-3} \mathrm{~Pa}\right)$ results in dense films (a), while the film morphology evolves from composite amorphous-nanocrystalline at $5 \mathrm{~Pa}$ (b), to nanogranular 10 and $100 \mathrm{~Pa}(\mathrm{~d}, \mathrm{e})$. A schematic depicting the formation of atom-by-atom growth (low vacuum) and cluster assembled growth (10 and $100 \mathrm{~Pa}$ ) is shown in e) and f), respectively. (g) The corresponding GIXRD diffractograms. An amorphous structure is found for background pressure of $2.1 \times 10^{-3} \mathrm{~Pa}$ and from 10 up to $200 \mathrm{~Pa}$. 
Figure 2 gathers a detailed TEM characterization of the films deposited at $2.1 \times 10^{-3}, 10$ and $100 \mathrm{~Pa}$ (see M ethods and Supplementary S1). In Figs. 2a, 2d and 2g, high angle annular dark field (HAADF) STEM shows that all films exhibit a nanolaminated structure alternating bright and dark nanolayers with an average period $\sim 4-5 \mathrm{~nm}$. Fig. 2 also shows STEM-EDX maps and line profiles showing the comparison between HAADF-STEM intensity and STEM-EDX. Interestingly, the films exhibit a compositional variation alternating $\mathrm{Cu}$-rich and $\mathrm{Zr}$-rich nanolayers together with $\mathrm{O}$ fluctuation which is present especially in the Zr-rich nanolayers. A lower percentage of 0 is found for the film deposited in low vacuum conditions $\left(2.1 \times 10^{-3} \mathrm{~Pa}\right)$. Similar features are observed in the XRR scans revealing the presence of satellite peaks, attesting the formation of a periodic layering along the growth direction. An example is shown in Fig. S9c for the 10 Pa sample reporting a chemical modulation of $5.7 \mathrm{~nm}$ period, while the mass density difference of the layers is $\sim 12 \%$ ( 6.9 and $\left.6.1 \mathrm{gcm}^{-3}\right)$, consolidating the STEM/EDX results showing a compositional variation between Cu-rich and Zr/O-rich layers of 8-10 at.\% (Fig. 2c and Supplementary S2).

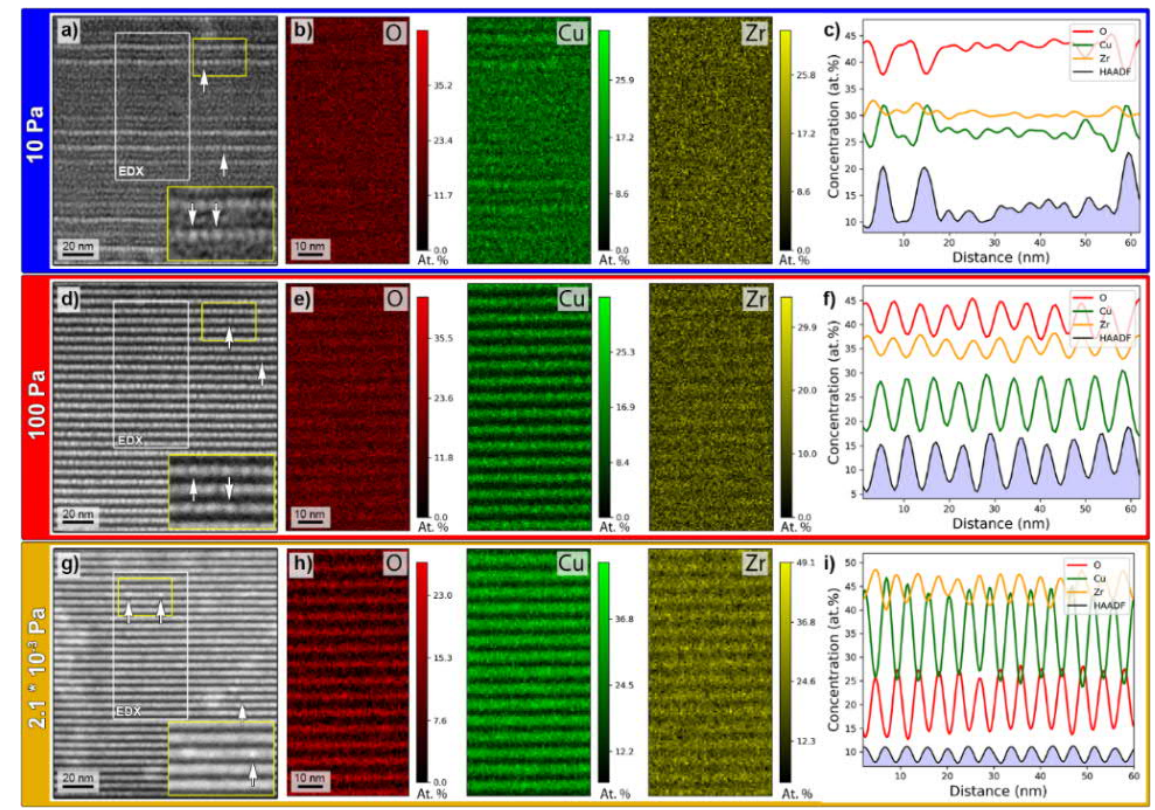

Fig. 2. High resolution HAADF-STEM images of ZrCu films deposited at 10 (a), 100 (d) and $2.1 \times 10^{-3} \mathrm{~Pa}(\mathrm{~g})$. (b, e, h) O, Cu and Zr STEM -EDX maps acquired in the area highlighted by a white rectangular in (a), (d) and $(g)$, respectively. $(c, f, i)$ Quantified chemical composition using line profile in the EDX maps of (b), (e) and (h) as well as HAADF-STEM intensity line profile from (a), (d) and (g), respectively. White arrows in (a), (d) and (g) indicate the presence of nanoclusters (see the enlarged insets highlighted by a yellow rectangular). 
M oreover, Fig. 2 shows that the films deposited at 10 and $100 \mathrm{~Pa}$ exhibit a less periodic arrangement of the nanolayers with strong lateral in-plane segregation and clustering (white arrows in Figs. 2a, 2d). Such nanoclustering is related with in-plume clustering formation favored at large background gas deposition pressures. In-plane segregation can also be observed even in the $2.1 \times 10^{-3} \mathrm{~Pa}$ sample as evidenced by nanoclusters within a single nanolayer (white arrows in Fig. 2g).

In Fig. 3, nano-beam-electron-diffraction (NBED, beam size of $1 \mathrm{~nm}$ ) 4D-STEM measurements on the films shown in Fig. 2 are presented in order to investigate the local atomic order in the Cu-rich or Zr/Orich nanolayers (details in Methods and Supplementary S3-4). In Figs. 3(a1) and 3(a2), mean 4D-STEM diffraction patterns calculated by combining all the NBED patterns from each nanolayer are shown for the film deposited at $10 \mathrm{~Pa}$ (see also Fig. S14), while Fig. 3(a3) reports the averaged 4D-STEM diffraction pattern on the entire scanned area which is compared to the conventional selected area electron diffraction (SAED) pattern shown in Figure 3(a4). Fig. 3c displays the radial intensity profiles I( $k$ ) ( $k$ being the scattering vector) determined from the diffraction patterns in Figs. 3(a1-4). The virtual darkfield maps of the two phases in Figs. 3(b1-2) were obtained by selecting specific regions from I(k) using virtual aperture (vertical dashed bands in Fig. 3c). These two maps are summed (Fig. 3(b3)) and compared with a HAADF-STEM image of the same region (Fig. 3(b4)). The same approach above was applied for the films deposited at 100 and $2.1 \times 10^{-3} \mathrm{~Pa}$. The results indicate that, in films deposited at 10 and $100 \mathrm{~Pa}$, the I(k) intensity profiles extracted from SAED patterns and the radial intensity profiles are very similar. However, 4D-STEM data reveal differences between the Cu-rich and Zr/O-rich phases. Indeed, the I(k) curve of the Zr/O-rich phase exhibits a first intense peak followed by a second weaker one typical of glassy materials, while the difference of intensity between the two peaks is significantly smaller in the I(k) curve of the Curich phase which can be attributed to the presence of crystalline phase. Indeed, HR-STEM images of these two films (10 and $100 \mathrm{~Pa}$ ) confirm the presence of very small crystalline clusters $(1-2 \mathrm{~nm})$ in the Cu-rich phase, while the Zr/O-rich phase exhibits a more 'disordered' structure (Fig. S11). This is also consolidated 
by calculating the normalized variance diffraction patterns and normalized variance profiles (Fig. S16). In

the film deposited at $2.1 \times 10^{-3} \mathrm{~Pa}$, the I(k) curve extracted from the SAED pattern exhibits two adjacent and distinct first intense peaks not reported for 10 and 100 Pa films. 4D-STEM data show that, the I(k) curve of the $\mathrm{Zr} / 0$-rich phase is quite similar to the ones obtained in the films deposited at 10 and $100 \mathrm{~Pa}$, while the curve corresponding to the $\mathrm{Cu}$-rich phase for the $2.1 \times 10^{-3} \mathrm{~Pa}$ appears very different with a single peak shifted to higher $k$, indicating significant changes of the nature of local order. 4D-STEM and HR-STEM did not reveal the presence of small crystallites in both nanolayers (Figs. S11, S16) in agreement with the limited in-plane clustering and a more 'disordered' nature of this film.

These results demonstrate that PLD deposition conditions produce well-defined nano-laminated films with two distinct phases having different chemical compositions and local atomic order (amorphous or crystal/amorphous hybrid nanostructure). This unique self-assembled nanostructure originates from the highly energetic PLD deposition conditions (laser energy and wavelength) which can induce a very fine segregation along the growth direction, favoring decomposition of (meta)stable ZrCu amorphous alloys into a Cu-rich and a Zr/O rich phases, similarly to NGs [43]. The additional in-plane segregation is due to local clustering favored at large deposition pressure $(10,100 \mathrm{~Pa})$ which convolute with a marked local order and, in selected areas, a tendency to nanocrystallization, as for BM Gs embedded with nanocrystals after annealing treatment [15]. This can also be favored by the presence of 0 promoting a covalent character to bonds, local ordering and nanocrystallization as also reported in Refs. [40, 41].

\subsection{Mechanical behavior}

The elastic and plastic properties have been determined by using BLS and nanoindentation, respectively (Fig. 4 and M ethods). The shear modulus (G), Young's modulus (E), and hardness (H) of TFM G deposited at $2.1 \times 10^{-3} \mathrm{~Pa}$ are equal to, respectively, $-46,130$ and $10 \mathrm{GPa}$, which is almost twice the literature results (namely $\sim 25,70-90$ and $6 \mathrm{GPa}$ ) for $\mathrm{ZrCu}$ film with equivalent composition but deposited by sputtering [37, 44]. The presence of $O$ [45] and the nanolayering structure [46] alter the local 
arrangement and provide a stiffer covalent character to the bonding. These characteristics also make more difficult the activation of permanent atomic rearrangements reflecting in a larger hardness. Nevertheless, the Poisson ratio $(v)$ maintains a high value $\sim 0.37$ close to homogeneous films $\sim 0.365$ [44]. Increasing the background gas pressure to $10 \mathrm{~Pa}$, both $\mathrm{G}$ and $\mathrm{E}$ reach even larger values equal to $\sim 58$ and $150 \mathrm{GPa}$, respectively. This increase is most presumably due to a higher amount of 0 and nanocrystalization in the Cu-rich nanolayer.

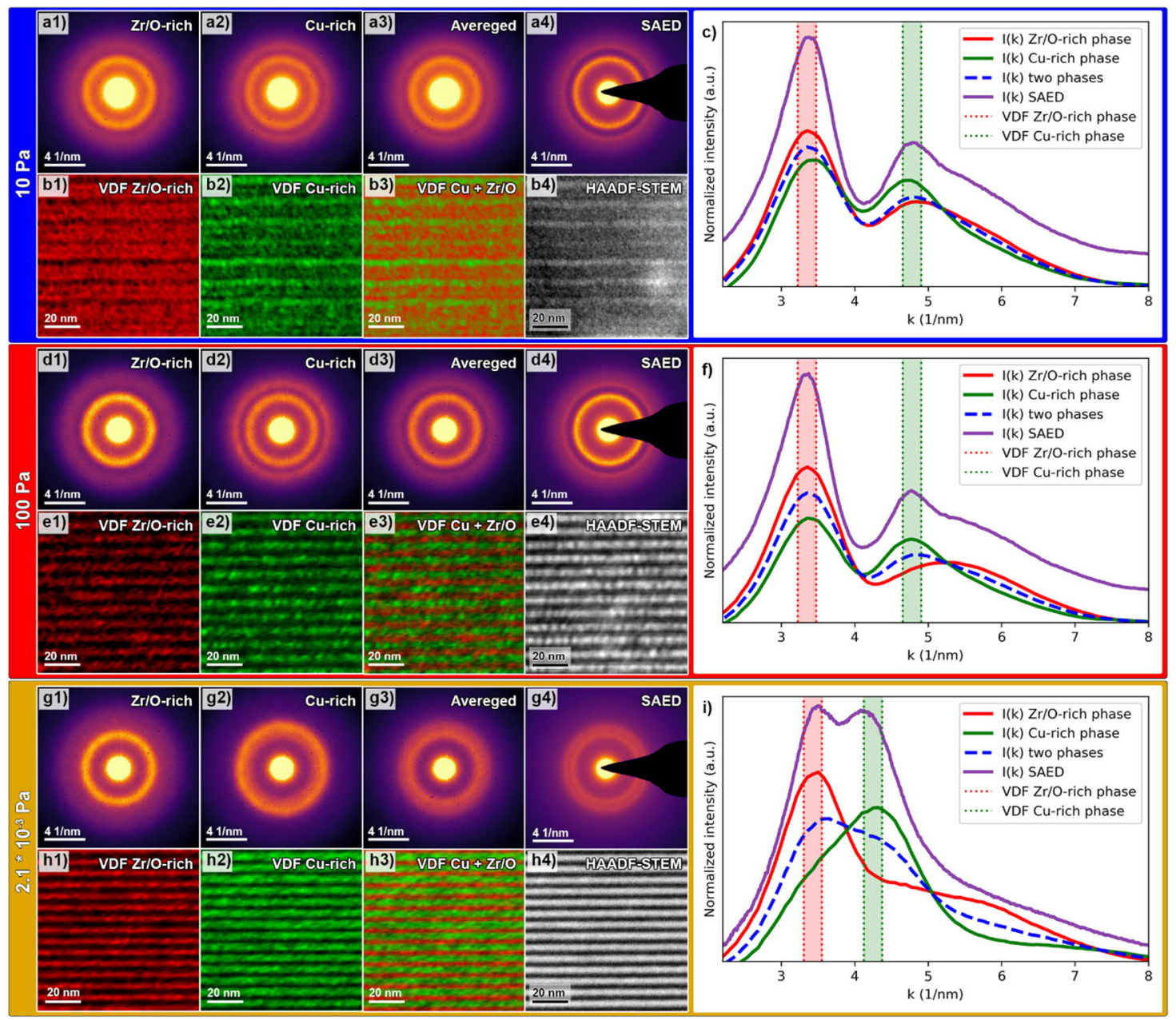

Fig. 3. 4D-STEM diffraction data for local crystal structure analysis of nanolaminated ZrCu films deposited at $(a, b, c) 10,(d, e, f) 100$ and $(g, h, i) 2.1 \times 10^{-3} \mathrm{~Pa}$. M ean NBED diffraction pattern for the Cu-rich and Zr/Orich phases ( $a 1$ and $a 2, d 1$ and d2, g1 and g2, respectively). Averaged NBED pattern over a total scan area and conventional SAED ( $a 3$ and $a 4, d 3$ and d4, g3 and g4, respectively). (c, f, i) Radial intensity profiles I(k) calculated from the mean and averaged NBED patterns as well as SAED. Virtual dark field maps of the two phases are generated by using a virtual aperture (indicated as vertical bands in radial intensity profiles) in (b1 and b2, el and e2, h1 and h2). Summed VDF maps of the two phases and HAADF-STEM image (b3 and b4, e3 and e4, h3 and h4, respectively). 
The enhanced covalent character in the nanolayers is indirectly confirmed by the reduction of $v$ down to $\sim 0.27$ for films deposited at $10 \mathrm{~Pa}$ pressure. This value is below the critical threshold $v_{\text {crit }}=0.315$ for which cracking is expected to occur instead of plastic SB [47]. In samples deposited at $100 \mathrm{~Pa}$, $\mathrm{G}$ and E decrease by $\sim 20 \%$ due to reduced mass density and to the more pronounced nanoclustering involving a higher fraction of interfaces with weaker bonds. At the same time, $\mathrm{H}$ only slightly decreases down to $\sim 8.5 \mathrm{GPa}$ presumably because the constraint upon atomic rearrangements due to the nanolayered structure is still efficient. Hence, for all deposition pressures, the elastic stiffness and $\mathrm{H}$ remain larger than in homogeneous $\mathrm{Zr}_{50} \mathrm{Cu}_{50}$ (\%at.) TFM Gs [37, 44] and ribbons [14].

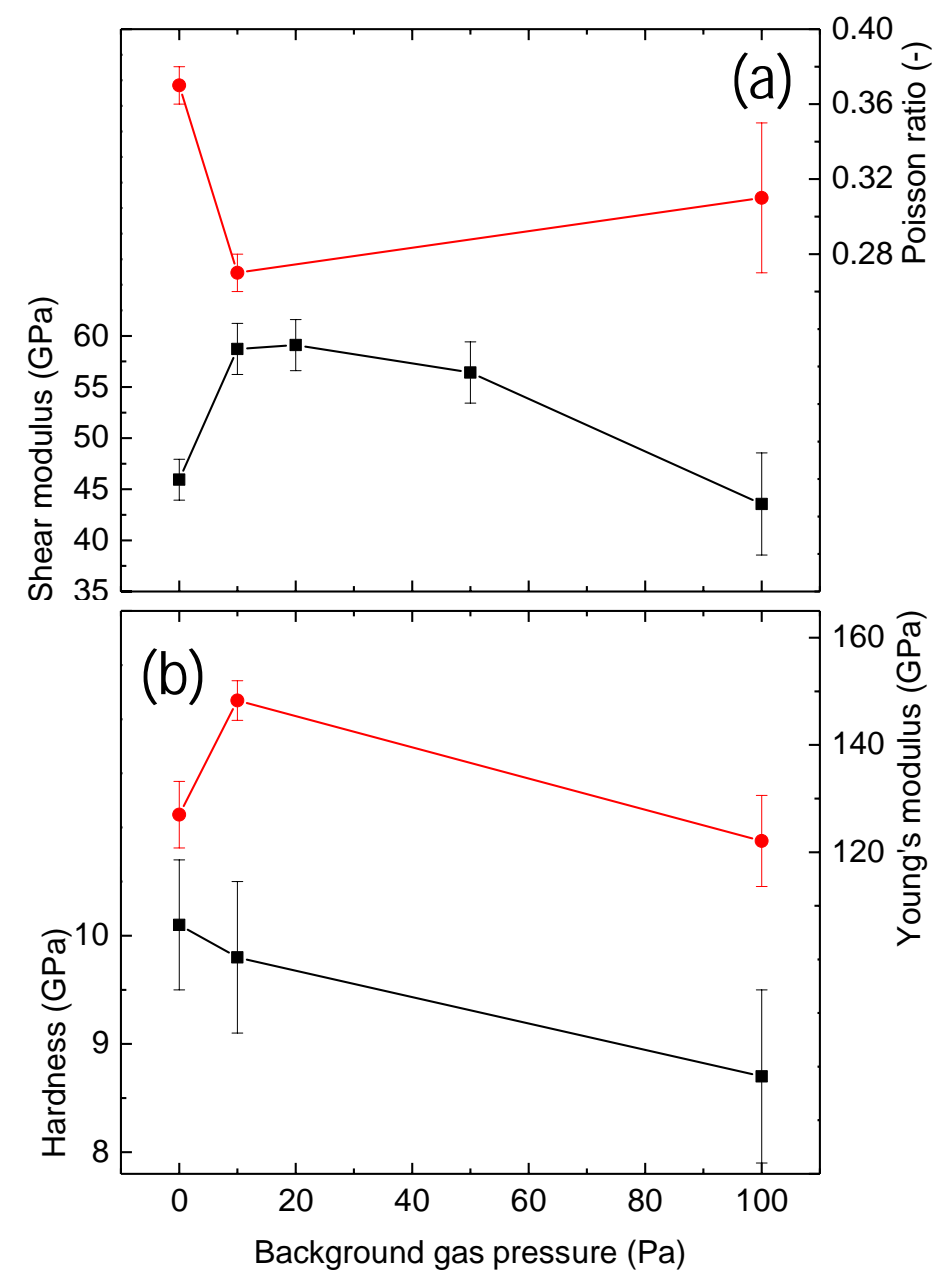

Fig. 4. (a,b) Variation of the shear and Young's moduli, Poisson ratio hardness as a function of the deposition pressure. 
In order to determine the full stress-strain response of the films and to link it with the mechanisms of deformation and fracture, quantitative in-situ TEM tensile tests have been performed on the $2.1 \times 10^{-3}$, 10 and $100 \mathrm{~Pa}$ films (Figs. 2 and 3). Cross-sectional specimens $(\sim 2 \times 0.4 \times 0.15 \mu \mathrm{m})$ were machined with FIB and mounted on a PTP device [48, 49] (Figs. 5a-d and M ethods). Fig. 5e presents the engineering stress-strain curves under load control mode with a loading rate of $0.1 \mu \mathrm{N} / \mathrm{s}$. The fully amorphous film $\left(2.1 \times 10^{-3} \mathrm{~Pa}\right.$ ) exhibits a large yield strength $\sigma_{\mathrm{y}} \sim 2.6 \mathrm{GPa}$ (in good agreement with nanoindentation $\sigma_{\mathrm{y}}-\mathrm{H} / 3$ ) combined with a reasonably good total elongation to failure of $-6 \%$, hence exhibiting the activation of some plasticity before failure in agreement with literature data on $\mathrm{Zr}_{65} \mathrm{Ni}_{35}$ and $\mathrm{Zr}_{51} \mathrm{Cu}_{49}$ TFM Gs deformed in tension $[5,6]$. This mechanical behavior involving a high strength and moderate ductility partly originates from a mechanical size effect, preventing the formation of mature SBs [6,50], and partly from the intimate nanolayered structure. Moreover, no internal delamination is observed, indicating strong adhesion between the $\mathrm{Cu}$-rich and $\mathrm{Zr} / 0$-rich nanolayers. The fracture angle is $-65^{\circ}$ with respect to the loading direction in agreement with M G specimens deformed in tension [3].

For the films deposited at 10 and $100 \mathrm{~Pa}$, the yield strength reduces down to $<2 \mathrm{GPa}$ but with a gain of total elongation to failure up to $\sim 9 \%$ and the presence of some degree of strain hardening. This must originate from the presence of a large density of interfaces including a high fraction of nanocrystal/amorphous boundaries which are not present in $2.1 \times 10^{-3} \mathrm{~Pa}$ films. A high amount of free volume or excess energy might be stored at these interfaces $[12,14]$ together with highly flexible local atomic environment atomic structure [51]. This leads both to a complex internal stress landscape and heterogeneous distribution of energy barriers associated to the activation of STZs. Hence, by increasing nano-clustering and the fraction of interfaces, STZs can be activated at a lower applied load $[13,52]$ (explaining the reduced yield strength) but also distributed in a much more homogenous way. The heterogeneity makes more difficult the percolation of extended defects and the generation of mature SB, leading to a higher ductility $[13,52]$ similarly to the deformation behavior of NGs $[12,14]$, reporting 
significantly larger deformation when compared to the standard M G counterparts, together with a lower yield strength. In addition, the formation of nanocrystals in Cu-rich layers provide an even more difficult propagation of SB improving ductility, see Ref. [15]. The origin of the strain hardening is most probably the result of the progressive activation of less fertile STZs and free volume zones in cluster assembled film, as also observed for BM Gs embedded with nanocrystals [3]. The 100 Pa samples, which exhibit a higher fraction of interfaces and a marked cluster assembled growth (including crystal/amorphous interfaces), report the highest total elongation to failure $(9.4 \%)$ combined to the lower yield strength. However, it can be noted that the PLD-deposited cluster assembled films maintain a very good combination of mechanical properties combining up to $\sim 40 \%$ larger ductility at the expense of $\sim 50 \%$ drop of the yield strength with respect e.g. nanoglasses [16] or multilayers [10]. The fracture plane for 10 and $100 \mathrm{~Pa}$ films (Figs. $5 f, g$ ) is $\sim 90^{\circ}$, indicating a disconnection of the cracking process from plastic SB.
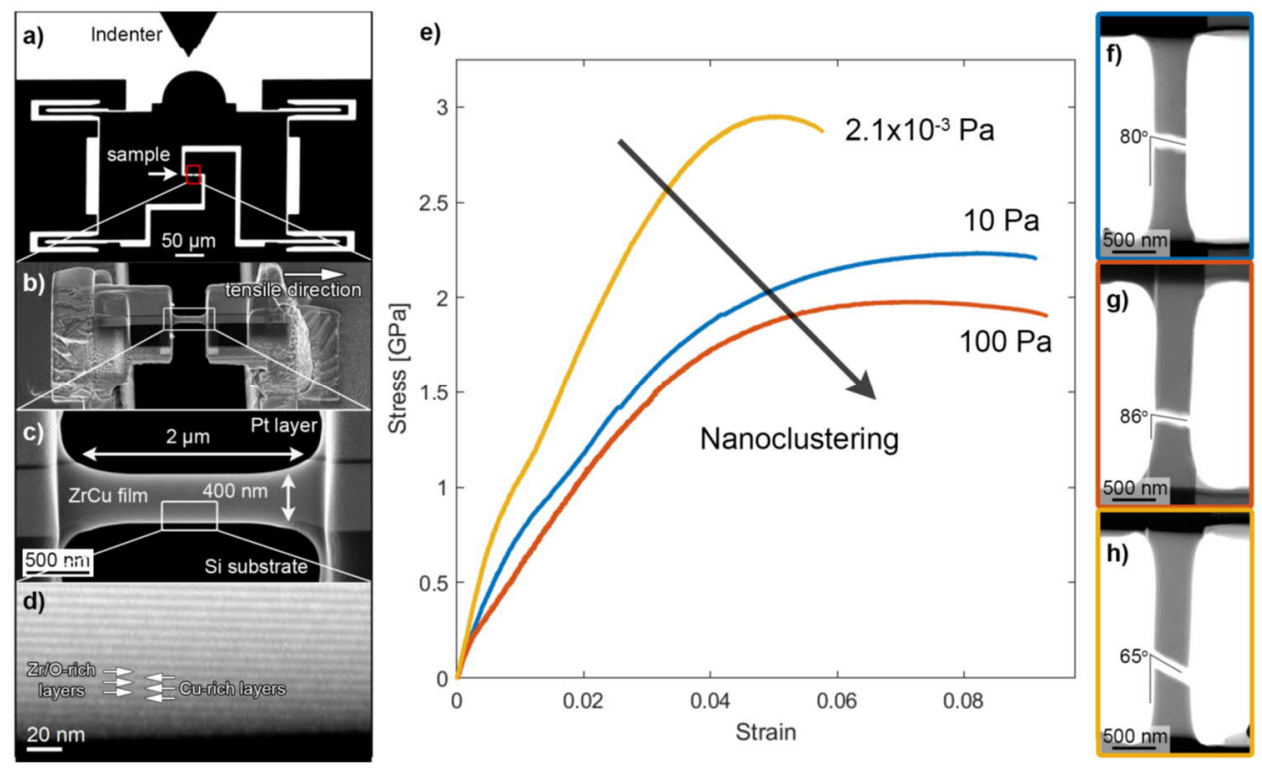

Fig. 5. Quantitative in situ TEM tensile testing. (a) Low magnification TEM image of the tip of diamond indenter and the PTP device used for quantitative in-situ TEM tensile experiments. The sample was mounted in the central area marked with a red box. (b, c) Magnified SEM images of the cross-sectional ZrCu film mounted on the PTP device. (d) High-resolution STEM image of the edge of the sample (marked with a white box in (c)), showing the nanolayered structure of the film after FIB thinning. (e-h) Engineering stress-strain curves and TEM snapshots after the fracture of $\mathrm{ZrCu}$ films deposited at $10 \mathrm{~Pa}(\mathrm{f}), 100 \mathrm{~Pa}(\mathrm{~g})$ and $2.1 \times 10^{-3} \mathrm{~Pa}(\mathrm{~h})$. 
In Fig. 6, digital image correlation was used to subtract the contrast of the image at plastic yielding from that of the image just before the fracture in the three films. It is worth noting that necking is more visible in the 10 and $100 \mathrm{~Pa}$ films where softening is more marked in the stress-strain curves of Figure 5. Similar results are obtained for notched samples deformed in tension in-situ TEM exhibiting stable crack growth [53]. Moreover, the presence of arrested nanocracks in the crystal-amorphous hybrid $10 \mathrm{~Pa}$ and 100 Pa films (black and white arrows) indicating the high fracture toughness of these films and stable crack growth. On the other hand, two crossing SB can be observed in the necking region of the $2 \times 10^{-3} \mathrm{~Pa}$ film prior to fracture (black and white arrow) in agreement with the fully amorphous microstructure of this film. Note that for all deposited sample the expected large rate sensitivity $m=0.02$ (obtained by nanoindentation on e.g. ZrNi TFMGs [8]) can prevent the development of a full necking behavior. However, still further investigations are needed to determine the exact failure nature of such nanostructured films by PLD. Moreover, we did not detect any 0 embrittlement, as in classical MG compositions [54, 55], as a result of extrinsic size effect combined with toughening related to the heterogeneous nanostructure [46]. On the contrary, we show that in the case of such glassy nanocomposites, the 0 addition can even boost the mechanical properties, as reported in high entropy alloys with formation of ordered Ti-Zr-O complexes [56], inducing preferential chemical bond formation between oxygen and Zr.

\section{Conclusions}

A novel class of nanostructured $\mathrm{Zr}_{50} \mathrm{Cu}_{50}$ (\%at.) TFM Gs has been discovered owing to the extreme out of equilibrium conditions associated to the pulsed laser deposition (PLD) method. These new nanostructured films show the following characteristics: 
- A large variety of film microstructures can be synthetized, including compact fully amorphous, and crystal/amorphous hybrid and amorphous nanogranular microstructures by simply changing the background gas pressure;

- Advanced TEM analysis reveals a unique nano-laminated atomic structure characterized by alternated layers exhibiting different chemical enrichment and local atomic order;

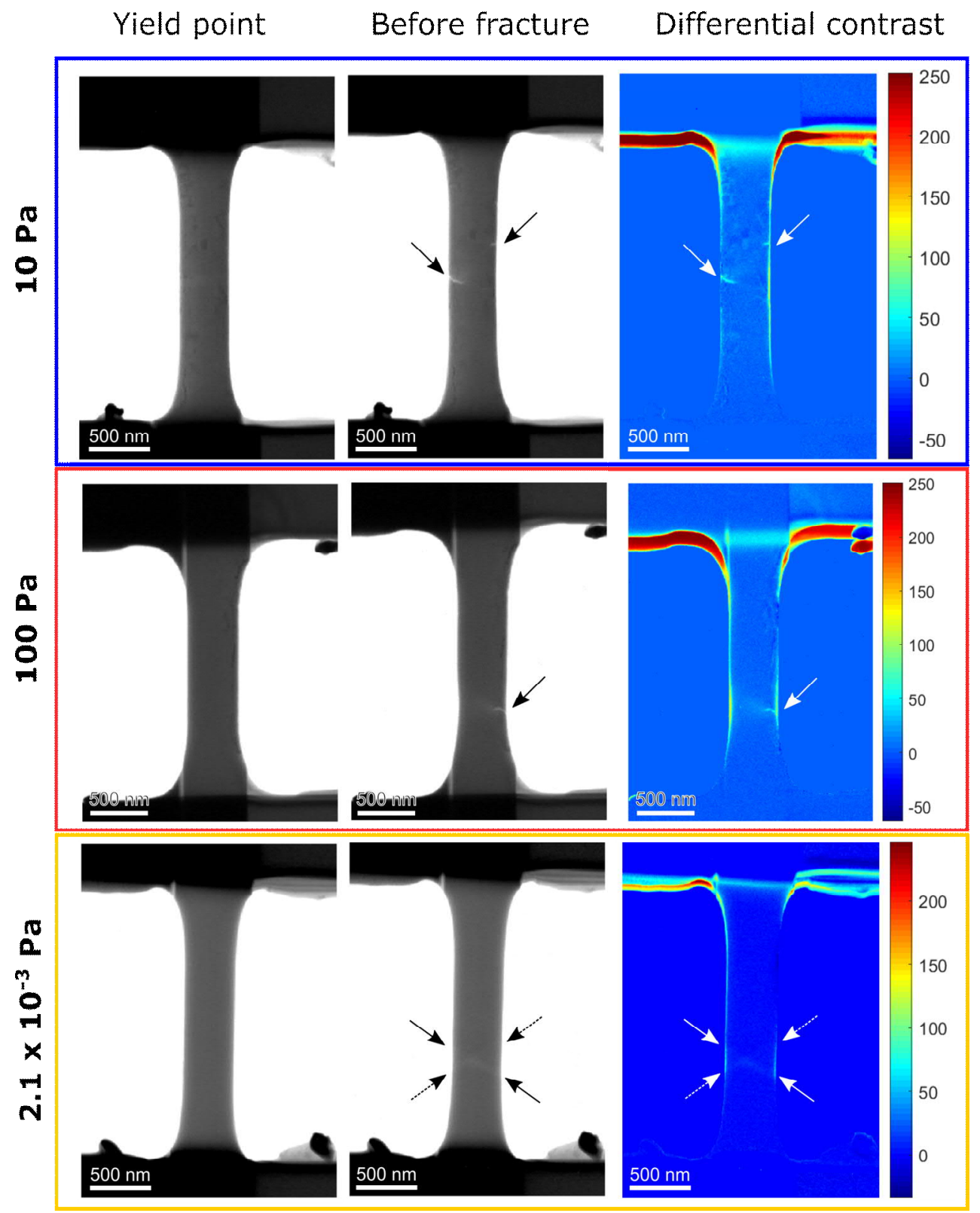

Fig. 6. Necking observations in $\mathrm{ZrCu}$ films deposited at $10 \mathrm{~Pa}, 100 \mathrm{~Pa}$ and $2.1 \times 10^{-3} \mathrm{~Pa}$, from comparison of frames taken at the yield point (left) and just before fracture (middle). Subtraction of the two images (differential contrast image in the right) shows the most developed neck in the $100 \mathrm{~Pa}$ and $2 \times 10^{-3} \mathrm{~Pa}$ films. 
- This self-assembled nanoarchitecture is at the basis of unique mechanical properties including high elastic modulus and hardness up to 145 and $10 \mathrm{GPa}$, respectively, for crystal/amorphous nanogranular glasses deposited at 10 Pa pressure;

- Quantitative in-situ TEM tensile tests confirm the high yield strength potential (up to $2.6 \mathrm{GPa}$ ) and outstanding total elongation to failure (up to $9 \%$ ). This product is significantly affected by the chemical fluctuation and nano-clustering with compact/nanogranular structure reporting low/large plasticity and high/low yield strength.

The physical origin of these unique mechanical properties is related to the local atomic order, free volume content and film architecture (nanoclustering and nanolayering), highlighting for the first time the possibility to produce novel TFMGs with different mechanical properties by tuning the local nanostructure. This nano-laminated structure offers a unique opportunity to investigate the evolution of the local order with plastic deformation by probing of single glassy phases and interfaces in-situ with 4DSTEM. This will open future scenarios to engineered TFM Gs with high structural performances.

\section{Acknowledgements}

H.I. is mandated by the Belgian National Fund for Scientific Research (FSR-FNRS). This work was supported by the Fonds de la Recherche Scientifique - FNRS under Grant T.0178.19 and Grant CDR-J011320F. We acknowledge funding for the direct electron detector used in the 4D stem studies from the Hercules fund 'Direct electron detector for soft matter TEM ' from the Flemish Government J.V acknowledges funding from the European Union's Horizon 2020 research and innovation program under grant agreement No 823717 - ESTEEM 3. A.O. has received partial funding from the GOA project "Solarpaint" of the University of Antwerp. A.B. and J.V. acknowledge funding through FWO project G093417N ('Compressed sensing enabling low dose imaging in transmission electron microscopy') from the Flanders Research Fund. M.G. and A.L.B acknowledge Chantelle Ekanem for support in PLD depositions. 


\section{References}

[1] M. Ashby, A. Greer, M etallic glasses as structural materials, Scr. Mater. 54(3) (2006) 321-326.

[2] C.A. Schuh, T.C. Hufnagel, U. Ramamurty, M echanical behavior of amorphous alloys, Acta Mater. 55 (2007) 4067-4109.

[3] A.L. Greer, Y.Q. Cheng, E. Ma, Shear bands in metallic glasses, Mater. Sci. Eng., R 74(4) (2013) 71-132.

[4] D. Tonnies, R. M aass, C.A. Volkert, Room temperature homogeneous ductility of micrometer-sized metallic glass, Adv. Mater. 26(32) (2014) 5715-21.

[5] L. Tian, Y.Q. Cheng, ZW. Shan, J. Li, C.C. Wang, X.D. Han, J. Sun, E. Ma, Approaching the ideal elastic limit of metallic glasses, Nat. Commun. 3:609 (2012) 1-6.

[6] M. Ghidelli, H. Idrissi, S. Gravier, J.-J. Blandin, J.-P. Raskin, D. Schryvers, T. Pardoen, Homogeneous flow and size dependent mechanical behavior in highly ductile Zr65Ni35 metallic glass films, Acta M ater. 131 (2017) 246-259.

[7] H. Idrissi, M. Ghidelli, A. Béché, S. Turner, S. Gravier, J.-J. Blandin, J.-P. Raskin, D. Schryvers, T. Pardoen, Atomic-scale viscoplasticity mechanisms revealed in high ductility metallic glass films, Sci. Rep. 9(1) (2019) 1-11.

[8] M. Ghidelli, S. Gravier, J.-J. Blandin, P. Djemia, F. M ompiou, G. Abadias, J.-P. Raskin, T. Pardoen, Extrinsic mechanical size effects in thin ZrNi metallic glass films, Acta M ater. 90 (2015) 232-241.

[9] Z.-D. Sha, P.S. Branicio, H.P. Lee, T.E. Tay, Strong and ductile nanolaminate composites combining metallic glasses and nanoglasses, Int. J. Plasticity 90 (2017) 231-241.

[10] J.-Y. Kim, D. Jang, J.R. Greer, Nanolaminates Utilizing Size-Dependent Homogeneous Plasticity of Metallic Glasses, Adv. Fun. Mater. 21(23) (2011) 4550-4554.

[11] Z. Fan, J. Li, Y. Yang, J. Wang, Q. Li, S. Xue, H. Wang, J. Lou, X. Zhang, "Ductile" fracture of metallic glass nanolaminates, Adv. Mater. Interfaces 4(21) (2017) 1700510.

[12] Y. Ivanisenko, C. Kübel, S.H. Nandam, C. Wang, X. M u, O. Adjaoud, K. Albe, H. Hahn, Structure and Properties of Nanoglasses, Adv. Eng. M ater. 20(12) (2018) 1800404.

[13] Y. Ritter, D. Şopu, H. Gleiter, K. Albe, Structure, stability and mechanical properties of internal interfaces in Cu64Zr36 nanoglasses studied by M D simulations, Acta M ater. 59(17) (2011) 6588-6593.

[14] S.H. Nandam, Y. Ivanisenko, R. Schwaiger, Z. śniadecki, X. Mu, D. Wang, R. Chellali, T. Boll, A.

Kilmametov, T. Bergfeldt, H. Gleiter, H. Hahn, Cu-Zr nanoglasses: Atomic structure, thermal stability and indentation properties, Acta M ater. 136 (2017) 181-189.

[15] K. Hajlaoui, A. Yavari, A. LeM oulec, W. Botta, F. Vaughan, J. Das, A. Greer, A. Kvick, Plasticity induced by nanoparticle dispersions in bulk metallic glasses, J. Non-Cryst. Solids 353(3) (2007) 327-331. [16] X.L. Wang, F. Jiang, H. Hahn, J. Li, H. Gleiter, J. Sun, J.X. Fang, Plasticity of a scandium-based nanoglass, Scripta Mater. 98 (2015) 40-43.

[17] P. Gondoni, M. Ghidelli, F. Di Fonzo, V. Russo, P. Bruno, J. Martí-Rujas, C.E. Bottani, A.L. Bassi, C.S. Casari, Structural and functional properties of Al: ZnO thin films grown by Pulsed Laser Deposition at room temperature, Thin Solid Films 520(14) (2012) 4707-4711.

[18] B.R. Bricchi, M. Ghidelli, L. M ascaretti, A. Zapelli, V. Russo, C.S. Casari, G. Terraneo, I. Alessandri, C. Ducati, A.L. Bassi, Integration of plasmonic Au nanoparticles in TiO2 hierarchical structures in a singlestep pulsed laser co-deposition, Mater. Design 156 (2018) 311-319.

[19] C. Ophus, Four-dimensional scanning transmission electron microscopy (4D-STEM): From scanning nanodiffraction to ptychography and beyond, M icrosc. Microanal. 25(3) (2019) 563-582.

[20] H. Yang, R. Rutte, L. Jones, M. Simson, R. Sagawa, H. Ryll, M. Huth, T. Pennycook, M. Green, H. Soltau, Simultaneous atomic-resolution electron ptychography and Z-contrast imaging of light and heavy elements in complex nanostructures, Nat. Commun. 7(1) (2016) 1-8.

[21] M. Treacy, J. Gibson, Variable coherence microscopy: A rich source of structural information from disordered materials, Acta Crystallogr. A 52(2) (1996) 212-220. 
[22] P. Pusey, J. Rarity, Measurement of Higher-Order Correlation Functions by Intensity CrossCorrelation Light Scattering, Le J ournal de Physique Colloques 46(C9) (1985) C9-43-C9-58.

[23] P.M . Voyles, J. Hwang, Fluctuation Electron M icroscopy, American Cancer Society2012, pp. 1-7.

[24] W. Stratton, P. Voyles, A phenomenological model of fluctuation electron microscopy for a nanocrystal/amorphous composite, Ultramicroscopy 108(8) (2008) 727-736.

[25] C. Ophus, P. Ercius, M. Sarahan, C. Czarnik, J. Ciston, Recording and using 4D-STEM datasets in materials science, M icrosc. M icroanal. 20(S3) (2014) 62-63.

[26] J. M ir, R. Clough, R. Maclnnes, C. Gough, R. Plackett, I. Shipsey, H. Sawada, I. MacLaren, R. Ballabriga, D. M aneuski, Characterisation of the Medipix3 detector for 60 and 80 keV electrons, Ultramicroscopy 182 (2017) 44-53.

[27] M. Nord, A. Ross, D. M cGrouther, J. Barthel, M. M oreau, I. Hallsteinsen, T. Tybell, I. MacLaren, Three-dimensional subnanoscale imaging of unit cell doubling due to octahedral tilting and cation modulation in strained perovskite thin films, Phys. Rev. Mater. 3(6) (2019) 063605.

[28] M. Nord, R.W. Webster, K.A. Paton, S. M cVitie, D. M cGrouther, I. MacLaren, G.W. Paterson, Fast Pixelated Detectors in Scanning Transmission Electron M icroscopy. Part I: Data Acquisition, Live Processing and Storage, arXiv preprint arXiv:1911.11560 (2019).

[29] W.C. Oliver, G.M. Pharr, M easurement of hardness and elastic modulus by instrumented indentation: Advances in understanding and refinements to methodology, J. Mater. Res. 19 (2003) 3-20. [30] J. Hay, B. Crawford, M easuring substrate-independent modulus of thin films, J. Mater. Res. 26 (2011) 727-738.

[31] D. Cattaneo, S. Foglio, C.S. Casari, A.L. Bassi, M. Passoni, C.E. Bottani, Different W cluster deposition regimes in pulsed laser ablation observed by in situ scanning tunneling microscopy, Surf. Sci. 601(8) (2007) 1892-1897.

[32] E. Besozzi, D. Dellasega, A. Pezzoli, C. Conti, M. Passoni, M.G. Beghi, Amorphous, ultra-nano- and nano-crystalline tungsten-based coatings grown by Pulsed Laser Deposition: mechanical characterization by Surface Brillouin Spectroscopy, M ater. Design 106 (2016) 14-21.

[33] D. Dellasega, G. Merlo, C. Conti, C.E. Bottani, M. Passoni, Nanostructured and amorphous-like tungsten films grown by pulsed laser deposition, J. Appl. Phys. 112(8) (2012) 084328.

[34] A. Uccello, D. Dellasega, S. Perissinotto, N. Lecis, M. Passoni, Nanostructured rhodium films for advanced mirrors produced by Pulsed Laser Deposition, J. Nucl. Mater. 432(1-3) (2013) 261-265.

[35] M. Ghidelli, S. Gravier, J.-J. Blandin, J.-P. Raskin, F. Lani, T. Pardoen, Size-dependent failure mechanisms in ZrNi thin metallic glass films, Scr. Mater. 89 (2014) 9-12.

[36] M. Apreutesei, C. Esnouf, A. Billard, P. Steyer, Impact of local nanocrystallization on mechanical properties in the Zr-59 at.\% Cu metallic glass thin film, M ater. Design 108 (2016) 8-12.

[37] M. Apreutesei, P. Steyer, L. Joly-Pottuz, A. Billard, J. Qiao, S. Cardinal, F. Sanchette, J. M. Pelletier, C. Esnouf, M icrostructural, thermal and mechanical behavior of co-sputtered binary Zr-Cu thin film metallic glasses, Thin Solid Films 561 (2013) 53-59.

[38] T. M inemura, J.J . van den Broek, J.L.C. Daams, Formation and thermal stability of amorphous Cu-Zr thin films deposited by coevaportaion, J. Appl. Phys. 63 (1987) 4426-4430.

[39] M. Ghidelli, S. Gravier, J.-J. Blandin, T. Pardoen, J.-P. Raskin, F. M ompiou, Compositional-induced structural change in ZrxNi100-x thin film metallic glasses, J. Alloys Compd. 615 (2014) S348-S351.

[40] B. Murty, D. Ping, K. Hono, A. Inoue, Direct evidence for oxygen stabilization of icosahedral phase during crystallization of Zr 65 Cu 27.5 Al 7.5 metallic glass, Appl. Phys. Lett. 76(1) (2000) 55-57.

[41] B. M urty, D. Ping, K. Hono, A. Inoue, Influence of oxygen on the crystallization behavior of Zr65Cu27. 5AI7. 5 and Zr66. 7Cu33. 3 metallic glasses, Acta Mater. 48(15) (2000) 3985-3996.

[42] E. Besozzi, D. Dellasega, V. Russo, C. Conti, M. Passoni, M.G. Beghi, Thermomechanical properties of amorphous metallic tungsten-oxygen and tungsten-oxide coatings, M ater. Design 165 (2019). 
[43] Y. Ivanisenko, C. Kübel, S.H. Nandam, C. Wang, X. M u, O. Adjaoud, K. Albe, H. Hahn, Structure and Properties of Nanoglasses, Advanced Engineering Materials 20(12) (2018).

[44] M. Apreutesei, P. Djemia, L. Belliard, G. Abadias, C. Esnouf, A. Billard, P. Steyer, Structural-elastic relationships of Zr-TL (TL=Cu, Co, Ni) thin films metallic glasses, J. Alloys Compd. 707 (2017) 126-131.

[45] S.V. Madge, D.V. Louzguine-Luzgin, J.J. Lewandowski, A.L. Greer, Toughness, extrinsic effects and Poisson's ratio of bulk metallic glasses, Acta Mater. 60 (2012) 4800-4809.

[46] P. Kontis, M. Köhler, S. Evertz, Y.T. Chen, V. Schnabel, R. Soler, J. Bednarick, C. Kirchlechner, G.

Dehm, D. Raabe, J.M. Schneider, B. Gault, Nano-laminated thin film metallic glass design for outstanding mechanical properties, Scripta Mater. 155 (2018) 73-77.

[47] Z. Liu, W. Wang, M. Jiang, Z. Zhang, Intrinsic factor controlling the deformation and ductile-to-brittle transition of metallic glasses, Phil. Mag. Lett. 94(10) (2014) 658-668.

[48] V. Samaee, M. Dupraz, T. Pardoen, H. Van Swygenhoven, D. Schryvers, H. Idrissi, Deciphering the interactions between single arm dislocation sources and coherent twin boundary in nickel bi-crystal, Nat. Commun. 12(1) (2021) 1-8.

[49] V. Samaee, R. Gatti, B. Devincre, T. Pardoen, D. Schryvers, H. Idrissi, Dislocation driven nanosample plasticity: new insights from quantitative in-situ TEM tensile testing, Sci. Rep. 8(1) (2018) 1-11.

[50] J.R. Greer, J.T.M. De Hosson, Plasticity in small-sized metallic systems: Intrinsic versus extrinsic size effect, Prog. M ater. Sci. 56 (2011) 654-724.

[51] Z. Fan, J. Ding, E. M a, Making glassy solids ductile at room temperature by imparting flexibility into their amorphous structure, Mater. Res. Lett. 6(10) (2018) 570-583.

[52] K. Albe, Y. Ritter, D. Şopu, Enhancing the plasticity of metallic glasses: Shear band formation, nanocomposites and nanoglasses investigated by molecular dynamics simulations, M ech. M ater. 67 (2013) 94-103.

[53] R.L. Narayan, L. Tian, D. Zhang, M. Dao, Z.-W. Shan, K.J. Hsia, Effects of notches on the deformation behavior of submicron sized metallic glasses: Insights from in situ experiments, Acta Mater. 154 (2018) 172-181.

[54] S.V. M adge, P. Sharma, D.V. Louzguine-Luzgin, A.L. Greer, A. Inoue, Mechanical behaviour of Zr-LaCu-Ni-Al glass-based composites, Intermetallics 19(10) (2011) 1474-1478.

[55] V. Keryvin, C. Bernard, J.-C. Sangleboeuf, Y. Yokoyama, T. Rouxel, Toughness of Zr55Cu30Al10Ni5 bulk metallic glass for two oxygen levels, J. Non-Cryst. Solids 352(26-27) (2006) 2863-2868.

[56] Z. Lei, X. Liu, Y. Wu, H. Wang, S. Jiang, S. Wang, X. Hui, Y. Wu, B. Gault, P. Kontis, Enhanced strength and ductility in a high-entropy alloy via ordered oxygen complexes, Nature 563(7732) (2018) 546-550. 